\title{
Estimating the Lost Economic Production Caused by Internal Displacement Because of Disasters
}

\author{
Mario A. Salgado-Gálvez ${ }^{1}$
}

Published online: 26 October 2018

(C) The Author(s) 2018

\begin{abstract}
Disasters are a large cause of internal displacement at the global level, in 2017 alone affecting more than 19 million people. This dimension of disaster risk is usually overlooked in many disaster risk management strategies and assessments. It is only very recently that efforts to quantify displacement risk and integrate that dimension into existing physical risk models have been made. A key component of internal displacement assessment is the quantification of its economic impacts, both direct and indirect, not only to make a figure available but to raise awareness and increase accountability among governments, stakeholders, policymakers, and decision makers. This article presents a novel and peril-agnostic methodology with which to estimate, using a scenario-based approach, the economic production lost because of internal population displacement. The methodology is applied by using as a triggering event the April 2015 Gorkha, Nepal M7.8 earthquake. The method quantifies the indirect cost caused by internal population displacement because of that event in terms of lost economic production and estimates the loss to be between USD 400 and 850 million.
\end{abstract}

Keywords Disability adjusted life years - Disaster risk · Internally displaced people $\cdot$ Lost economic production $\cdot$ Disaster risk assessment

Mario A. Salgado-Gálvez mario.sal.gal@gmail.com

1 Centre Internacional de Metodes Numerics en Enginyeria (CIMNE), 08034 Barcelona, Spain

\section{Introduction}

At the global level and historically, disasters have induced more internal displacement of people than any other cause, including conflicts and violence. In 2017 alone, almost 19 million internally displaced people (IDPs) because of disasters were registered, compared to 11.8 million who relocated to another part of their homeland because of conflict (IDMC 2018). An IDP is defined as a person who is forced to flee his or her home because of a triggering event, but who remains within the borders of the country of origin. Internal displacement, despite the evidence of its relationship with disasters, is a dimension that is usually overlooked in most risk assessments. Only in the recent past has the topic started to gain attention, something that is reflected in the development of prospective displacement risk models and also rigorous and transparent databases that account for this dimension.

Since 2008, the Internal Displacement Monitoring Center (IDMC) ${ }^{1}$ has kept records of IDPs caused by disasters. Since then, new internal displacements associated with disasters occur every year and affect mainly low and low-middle income countries (IDMC 2018). On average, since 2008 more than 25 million IDPs have been recorded per year at the global level, taking into account only sudden-onset events such as hurricanes, floods, storms, earthquakes, and wildfires. This is a figure that without doubt reflects the challenges posed not only from the humanitarian perspective but also from the sustainability standpoint. This figure also highlights failures in development and in the creation of robust disaster risk and environmental change strategies, and reflects the perpetuation of some of the poverty drivers of disasters. Existence of these

\footnotetext{
${ }^{1}$ http://www.internal-displacement.org.
} 
factors indicates that more effort and greater development spending are needed to address these pending risk identification, risk management, and policy-making tasks properly.

In 2016, IDMC also developed a global disaster displacement risk model-GDDRM-that made use of the hazard, exposure, vulnerability, and risk datasets of the United Nations Office for Disaster Risk Reduction (UNISDR). Incorporated in UNISDR's Global Risk Model (GRM), these datasets allowed the estimation of the number of IDPs, with global coverage and in a probabilistic way, in terms of average annual and probable maximum productivity losses (Ginnetti et al. 2017) linked to different types of natural hazards. The GDDRM model represents a milestone in the IDP field because it makes possible a first quantification of displacement risk due to disasters and explicitly considers and integrates the IDP dimension into the disaster risk management field. At the same time, the GDDRM has provided evidence that suggests that displacement associated with disasters will follow a similar increasing trend to the one observed until now (IDMC 2017).

Internal displacement is closely linked to all 17 Sustainable Development Goals (SDGs) established by the United Nations (UN 2015) in which IDPs are considered as part of a vulnerable group that should not be left behind. Cazabat (2018) provides an updated summary and explanation of the linkages between SDGs and internal displacement. The main conclusion drawn from Cazabat's analysis is that all SDGs impact internal displacement and, at the same time, internal displacement impacts all SDGs. Related to the displacement risk topic is the question of what the economic impacts (direct and indirect) are, since internal population displacement causes both great human suffering to individuals and important disruptions at the societal level. Disaster and displacement risk analysis not only raise awareness and communicate the results to governments, stakeholders, policymakers, and decision makers. These analyses also improve societal understanding of who should bear the costs associated with internal displacement. By looking only at the direct impacts of internal displacement, a vast share of the related economic losses is missed, mainly those impacts related to human capital and productivity. Given the lack of data to assess and monitor these dimensions, the use of correlated indicators, such as the lost economic production variables developed and explained in this article, are useful for policymakers. Although there are several publications in which the cost of disasters, either estimated in retrospective or prospective manner, are quantified (for example, the UNISDR Global Assessment Report (GAR) publications since 2009), to date only one study by the World Bank (2012) has been conducted. This work focuses solely on the direct impacts at national and regional scales, whereas at the local level only qualitative approaches have been applied (Amirthalingam and Lakshman 2009).

To answer our question, the methodology proposed in this article was developed in which a component of the disability adjusted life years (DALY) concept is adapted and used. The DALY metric (WHO 2013) has been previously used in both retrospective and prospective risk assessments (Noy 2014; Salgado-Gálvez, Bernal et al. 2016; UNISDR 2017). This metric allows more explicit consideration of the human dimension, mostly in terms of casualties and indirect economic effects such as the lost production. The disability adjusted life year (DALY) is a commonly used metric in the public health field. It was developed to quantify the burden of disease through comparison of overall health and life expectancy in different countries. One DALY corresponds to one lost year of healthy life. DALYs are estimated by adding two different components, denoted as YLD and YLL, respectively, as follows:

$\mathrm{DALY}=\mathrm{YLD}+\mathrm{YLL}$

YLD represents the adjusted number of years lived with any kind of disability, whereas the YLL is the number of years of life-lost due to premature mortality. YLD is calculated considering recovery times together with the decrease in any capability because of the disease until the moment of death, whereas YLL is calculated as the number of deaths multiplied by the life expectancy at the age of death. Altogether, DALY is calculated as the sum of the number of adjusted life years with disability and the number of life-lost years due to premature mortality (Larson 2013; WHO 2013; Devleesschauwer et al. 2014).

Based on one of the ideas behind the DALY, SalgadoGálvez, Bernal et al. (2016) made estimations of the average annual lost economic production because of premature deaths caused by earthquakes. That methodology only considered fatalities because of the collapse of buildings, which were estimated using different modules of the Comprehensive Approach to Probabilistic Risk Assessment (CAPRA) platform (Cardona et al. 2012). In this article, our interest is in the first component (YLD), which can be used to estimate the total number of life-lost years because of internal displacement and quantify the effects in terms of lost economic production. This methodology incorporates the YLD component into the IDPs field by accounting for both the number of internally displaced people and the length of the displacement in a (temporary) new setting. To estimate these factors, two different types of functions are developed, closely related to the structural damage that can be calculated by using risk assessment tools such as CAPRA. Instead of calculating the number of years lived with any degree of 
disability, the cumulative length of displacement after summing the time contribution of all IDPs in the affected region is estimated. The number of years is later combined with macroeconomic indicators, such as the GDP per capita, to estimate the lost economic production because of the internal displacement triggered by the event considered in the analysis.

The DALY metric uses an egalitarian principle where all persons are assumed to contribute in the same way at the time of aggregating the number of either life-lost years due to premature mortality or the number of years lived with any kind of disability. This underlying assumption also holds in the proposed methodology in our study, meaning that all years of internal displacement count in the same way regardless the characteristics (for example, socioeconomic, income, gender, educational, cultural, hierarchical) of the person who is displaced.

The proposed methodology was used to estimate the lost economic production because of internal displacement in Nepal, considering as a triggering event the Gorkha April 2015 M7.8 earthquake. Seismic hazard ground motion intensities were obtained from the data published by the United States Geological Survey (USGS), whereas the exposure database was adapted from the openly available UNISDR data (risk.preventionweb.net). ${ }^{2}$ Also, relationships of two different types were developed to first estimate the overall number of IDPs, and second, estimate the length of the displacement. Risk assessment was performed using the same tool as in IDMC's GDDRM. The obtained results show that the lost economic production because of the internal displacement caused by this earthquake is between USD 400-850 million, a value that adds to the direct losses of that event, estimated at as much as half the GDP of the country in 2015 .

\section{Methodology}

The proposed methodology is explained in detail in this section, together with the assumptions that are made at each of the stages. This methodology can be applied to triggering events of different types, such as earthquakes, tsunamis, landslides, floods, and hurricanes, if data that characterize the geographical extent and distribution of hazard intensities are available. Also, the methodology is fully scalable, meaning that when data are available, it can be used at urban, subnational, and national levels.

\footnotetext{
2 https://risk.preventionweb.net/capraviewer/main.jsp?tab=7\&map center $=0,1123252.6982849 \&$ mapzoom $=2$.
}

\subsection{Selection of the Event of Interest}

The first stage of the proposed methodology corresponds to the selection of the triggering event. The trigger can have different origins (for example, earthquake, tsunami, flood) and can be either a historical or a future event, which, although not having yet occurred, is known to be possible in the domain under study (that is, the maximum credible event).

Data requirements for the hazard component are the footprints that describe the geographical distribution of hazard intensities and are available in terms of intensity measures that correlate well with the structural damage (for example, spectral acceleration for earthquakes; water depth for floods). With this approach, cascading events can also be considered, meaning that, for instance, if excess rainfall triggers a flood or a landslide, the damage inflicted on residential units by the different hazards can be determined. Care must be taken when considering a multihazard approach to ensure that the loss estimation considers the simultaneous participation of different hazard intensities to avoid either under or overestimations of the risk (Ordaz 2015).

\subsection{Estimation of Structural Damage in the Domain Under Study}

Besides the hazard data, exposure and vulnerability inputs are needed for the damage and loss estimation. Exposure databases must include attributes that characterize the structural components of each asset that is susceptible to damage due to the action of the considered hazard and that is located within the domain under study. For each of the assets, a set of attributes are described such as construction material, age, number of stories and main use, among others. These characteristics allow the definition of building classes or typologies, which group elements with characteristics in common. For the estimation of IDPs, an entry in the exposure database must reflect also their human occupancy. Even if population is a dynamic exposure parameter, since only the residential sector is considered in this methodology, the distribution of the total population among the identified buildings is required. These exposure databases can be developed at different resolution levels depending not only on the scope of the assessment and the available resources, but also on the available data.

For each of the identified building classes, a unique physical vulnerability relationship needs to be assigned for each of the hazards of interest. This determination provides a connection between different hazard intensity values and the expected damages and losses in each case. 
Fig. 1 Binary relationship for the estimation of IDPs in masonry units in case of earthquakes

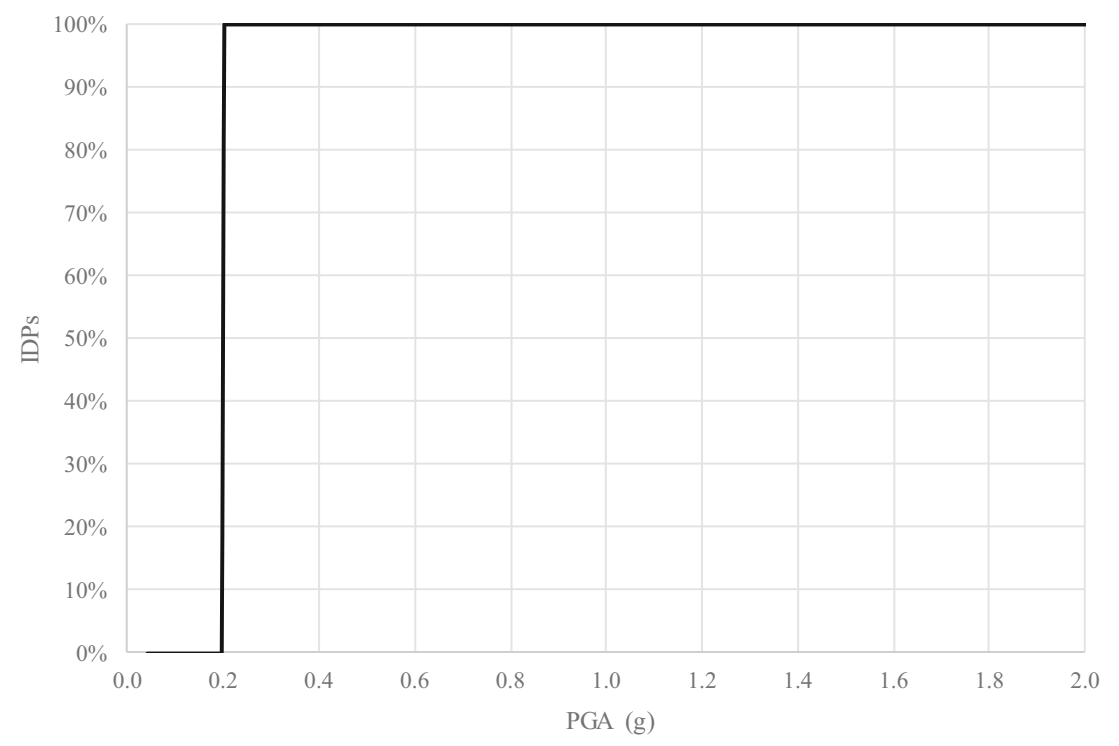

The damage and loss assessment stage follows an eventbased approach that uses the methodology proposed by Ordaz (2000). In our case, a deterministic approach is used from the temporal perspective, which considers that the event has already occurred and assigns an occurrence frequency equal to 1.0. From the damage and loss perspective, its assessment can be considered as fully probabilistic since the uncertainties related to hazard and structural vulnerability components can be quantified and propagated. The full details of the methodology are available in SalgadoGálvez, Zuloaga-Romero, Bernal et al. (2014). The scenario-based approach has been used in other studies to validate and calibrate different components of catastrophe risk models (Salgado-Gálvez, Barbat et al. 2016; Lamego et al. 2017). Losses are calculated using the following expression:

$v(l)=\sum_{i=1}^{N} \operatorname{Pr}\left(L>l \mid\right.$ Event $\left._{\mathrm{i}}\right) \cdot F_{A}\left(\right.$ Event $\left._{\mathrm{i}}\right)$

where $v(l)$ is the exceedance rate for loss of loss $l, N$ is the total number of hazard events, $F_{A}$ (Event ${ }_{i}$ ) is the annual frequency of occurrence of the $i$ th hazard event, and $\operatorname{Pr}\left(L>l\right.$ |Event $\left.{ }_{i}\right)$ is the probability of exceeding $l$, given that the $i$ th event has occurred. When a single event approach is selected, $N$ is equal to 1 , as its occurrence frequency, $F_{A}$. For the selected event, with the hazard intensities in the domain under study and for each entry included in the exposure database, the losses are calculated using the vulnerability functions assigned to each building class. This process is subsequently repeated for each entry. Once the assessment is finished, each entry in the exposure database will have associated a mean damage ratio (MDR) that will be used in the following stage.

\subsection{Estimation of the Number of IDPs Because of Damage in Residential Units}

The definition of IDP used in this methodology is the same provided in the introduction of the article. A person is considered as internally displaced if he or she must leave home either because of a preventive evacuation before the occurrence of the event or because the residential unit has suffered a degree of damage that makes it unsafe for immediate use. Also, it is assumed that all displacement occurs within the borders of the affected country. For the estimation of IDPs, different hazard intensity thresholds are assigned to the building classes. When these values are exceeded, it is assumed that their immediate occupation is not safe. Even if only for a matter of hours, the inhabitants cannot return to their homes and are classified as IDPs. Figure 1 shows an example of these binary relationships for the case of earthquakes and masonry units, where once peak ground acceleration (PGA) has exceeded approximately $0.2 \mathrm{~g}$, all the occupants of that residential unit are considered as IDPs.

\subsection{Estimation of Cleaning, Repair, and Recovery Times}

FEMA (2017a, b), the Federal Emergency Management Agency, provides reference recovery times for residential units, classified into single family and multifamily structures, as a function of either hazard intensities or structural damage states. For the case of floods, these relationships are directly related to water depth, whereas for earthquakes and hurricanes they are available in terms of structural damage states. For the second case, using the MDR obtained in stage 2 (Sect. 2.2), an indicative cleaning, 
Table 1 Relationships between mean damage ratio (MDR) ranges and structural damage states

\begin{tabular}{ll}
\hline MDR $(\%)$ & Structural damage state \\
\hline $0-2$ & None \\
$2.1-15$ & Slight \\
$15.1-30$ & Moderate \\
$30.1-55$ & Extensive \\
$55.1+$ & Complete \\
\hline
\end{tabular}

repair, and recovery time can be assigned to each affected building.

In the structural engineering field (on which most of the assumptions of this stage are based), qualitative damage states are widely used for the development of vulnerability models (for example, by FEMA in the United States or the RISK-UE project in Europe (Mouroux and Le Brun 2006), among others). These damage states are classified into different descriptions (usually with 4 or 5 categories) and there is no standard for their definition or classification.

In our methodology, the five structural damage states used by HAZUS (FEMA 2017b) are used, since the repair times have been chosen from that reference. Each of these damage states has a description (FEMA 2017b) and based on them, a linkage between the damage and MDRs obtained in stage 2 is made. For this linkage, values found in the disaster recovery literature can be used, which consider not only the direct physical damage but other socioeconomic and resilience factors that are known to have a relevant role in this aspect (Cardona 2001; Aijazi 2014; Pribadi et al. 2014; Mamula-Seadon 2015; SalgadoGálvez, Zuloaga Romero, Velás1uez et al. 2016). The values used are shown in Table 1.

According to each damage state, the number of years needed for a complete recovery of each residential unit (classified into single or multifamily) is shown in Table 2. These values correspond to the proposal of FEMA (2017b) that is to date the most reliable and open data source for these purposes. These values have been calibrated with data from the United States (mainly from California after the Loma Prieta and Northridge earthquakes), and their use can be extended to other regions when no information is available. On the other hand, Fig. 2 shows an example of the recovery function based on MDR for multifamily dwellings.

\subsection{Estimation of the Length Aggravating Factor Based on the Overall Damage}

In addition to the estimation of the MDR for each asset included in the exposure database, as performed in stage 2 (Sect. 2.2), and used in stage 4 (Sect. 2.4) for the estimation of cleaning, repair, and recovery times, a delay factor based on the overall MDR for the whole domain under study (for example, city or country) is also introduced.

This is founded on the logic that the largest overall damage within the domain under study results in the most complicated recovery and repair process because of scarcity of construction materials and a possible demand surge for materials and labor that can exist. The delay factor values proposed in the model are shown in Table 3. The definition of these factors is subjective and aims to highlight the relevance that the demand surge may have on the length of the recovery processes. Specific values could be obtained at local or regional scale to better capture this issue after a particular event.

Once the recovery time for all residential units is known, this time represents the displacement length since it is assumed that once the affected structures are safe to be used again, IDPs will return home. This is an assumption that omits cultural, social, and economic factors and incentives that cannot be modeled.

\subsection{Estimation of the Number of Life-Lost Years Because of Internal Displacement}

This stage performs the combination of the outcomes of stages 3, 4, and 5 (Sects. 2.3, 2.4, and 2.5). With them, the total number of life-lost years because of internal displacement (YLD), in the domain under study, is obtained. YLD is estimated in the following way:

$$
\begin{aligned}
\mathrm{YLD}= & \sum_{i=1}^{N}\left(\text { Recovery time }_{i} * \mathrm{IDP}_{i}\right) \\
& +\sum_{j=1}^{M}\left(\text { Recovery time }_{j} * \mathrm{IDP}_{j}\right)
\end{aligned}
$$

\begin{tabular}{|c|c|c|c|c|c|}
\hline \multirow[t]{3}{*}{ Building type } & \multicolumn{5}{|c|}{ Recovery time (in years) } \\
\hline & \multicolumn{5}{|c|}{ Structural damage state } \\
\hline & None & Slight & Moderate & Extensive & Complete \\
\hline Single family unit & 0 & 0.014 & 0.33 & 1.0 & 2.0 \\
\hline Multifamily unit & 0 & 0.028 & 0.33 & 1.333 & 2.667 \\
\hline
\end{tabular}

Table 2 Recovery time (in years) for single and multifamily dwellings by structural damage states 
Fig. 2 Recovery times based on MDR for multifamily units

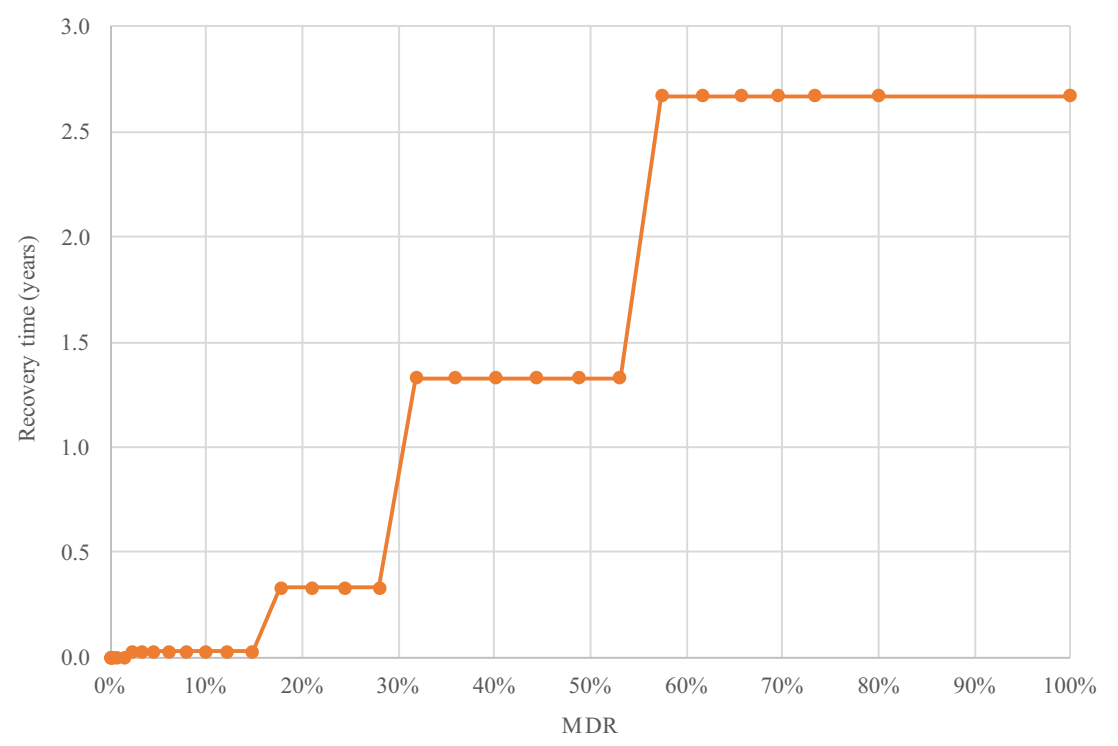

Table 3 Delay factors per overall MDR levels

\begin{tabular}{ll}
\hline MDR $(\%)$ & Delay factor \\
\hline $0-2$ & 1 \\
$2.1-5$ & 1.1 \\
$5.1-10$ & 1.3 \\
$10.1-20$ & 1.5 \\
$20+$ & 1.8 \\
\hline
\end{tabular}

where $N$ is the number of individual units, $M$ the number of multifamily units, $\mathrm{IDP}_{i}$ the internal displaced people who inhabited individual units, and $\operatorname{IDP}_{j}$ the internal displaced people who inhabited multifamily units.

\subsection{Estimation of the Total Number of Employed IDPs}

Using the population distribution (in ranges of at least 5-10 years), the share of those who are within the workingage range is obtained. Since working-age legal conditions can vary from place to place, the one that is applicable for the domain under study should be used. If that information is not clear, either because legislation on the topic does not exist or because its enforcement is poor, reference values such as the ones used by the OECD-those between 15 and 64 years (OECD 2018)—can be used.

This share of people is also affected by the labor force participation rate to reflect the number of people, within the working age, who are either employed or actively seeking a job. Finally, to consider only those within the labor force who are employed, the unemployment rate of the domain under study is also considered. In this case, it is assumed that the share of working-age people within the individual or multifamily dwellings is the same, so no differentiation at all is made at this point.

The estimation of this value can be performed in the same way as shown in Eq. 3, with the difference that only the share of employed IDPs is considered.

$$
\begin{aligned}
& \mathrm{YLD}_{\text {employed }}=\sum_{i=1}^{N}\left(\text { Recovery time }_{i} * \operatorname{IDP}_{i(\text { employed })}\right)
\end{aligned}
$$

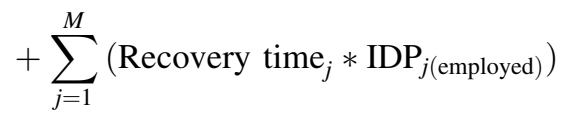

\subsection{Estimation of the Lost Economic Production Because of Internal Displacement}

In this final stage, based on the overall YLD for the chosen event, and considering only those associated to the working-age group, the lost economic production (LEP) is estimated in the following way:

$\mathrm{LEP}=\mathrm{YLD}_{\text {employed }} * \mathrm{GDP}_{\text {percapita }}$

where LEP is the lost economic production based on an egalitarian principle that assumes all individuals (IDPs) contribute in the same manner to economic output. Because GDP per capita has been used as an indicator of how much each person contributes to output (GDP), it is likely an underestimation of the lost economic production occurs, since it is assumed that even those who are not within the labor force contribute something to it. For this reason, the need to explore other metrics directly related to production (for example, GDP per employed person), with emphasis on the most vulnerable population (from a socioeconomic perspective), remains. 


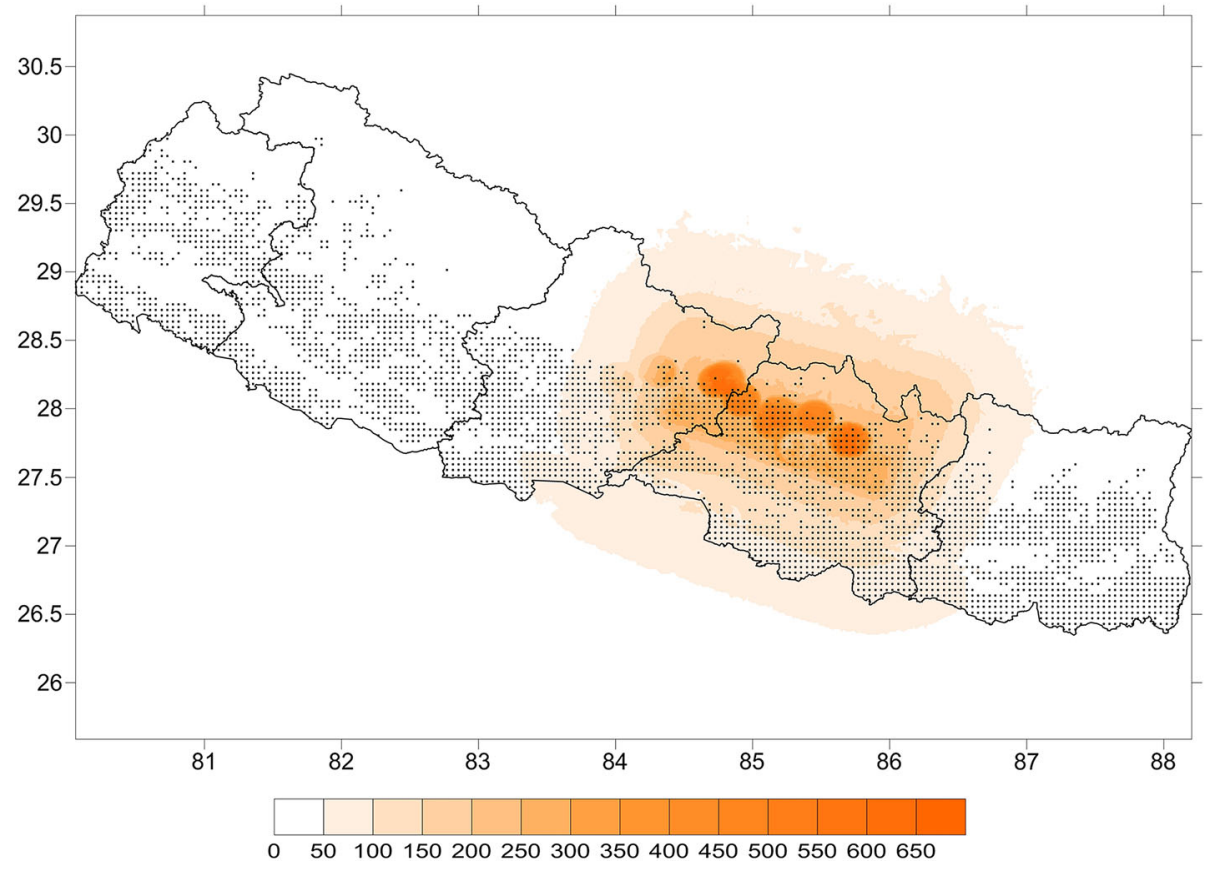

Fig. 3 PGA (gal) for the Gorkha April 2015 earthquake in Nepal

\section{Case Study: The Gorka, Nepal April 2015 Earthquake}

Our methodology was applied in Nepal by taking the April 2015 Gorkha M7.8 earthquake as the triggering event for internal population displacement. This event killed approximately 9000 people, injured more than 22,000, and damaged hundreds of thousands of dwellings across the country in rural and urban locations (Zhao 2016). The immediate economic impact was estimated by the local government to be as much as half of the country's GDP, but the consequences for the economy due to the internal displacement triggered by this earthquake have not been quantified.

Hazard footprints and ground motion intensities in terms of spectral accelerations for the M7.8 earthquake were obtained from those data published by the USGS (2015), which describe the geographical distribution of ground motion in the domain under study as shown in Fig. 3. Accelerations are shown in gal and additionally, the dots indicate the location of the residential units as per the $5 \times 5 \mathrm{~km}$ exposure database used in this study.

The exposure database corresponds to the one developed by De Bono and Chatenoux (2015) in the framework of GAR15 (UNISDR 2015) but only considers the residential sector at both urban and rural locations. Also, the physical earthquake vulnerability functions from UNISDR's Global Risk Model (GRM) were used (Cardona et al. 2014). The exposure database used herein considers different building classes, on which for instance, adobe block and unreinforced brick masonry have an important share, followed by reinforced concrete structures. More details about the building classes considered in Nepal and how the values were derived can be found in De Bono and Chatenoux (2015).

The estimates of MDR were obtained using the CAPRA-GIS tool that performs probabilistic damage and loss assessments following the methodological framework developed by Ordaz (2000). Each exposed asset in the exposure database was assigned a unique vulnerability function, which, as mentioned before, provides a relationship between the hazard intensities and the loss levels. When normalized by the exposed values, MDRs can be obtained. Figure 4 shows the MDR distribution in Nepal after performing the damage assessment using the abovementioned datasets. Only direct losses are accounted for at this stage.

Based on the MDRs, the estimation of the cleaning, repair, and recovery times is performed. The differentiation between single family and multifamily units is made by assuming that buildings of 1 or 2 stories fall in the first category whereas the others are considered as multifamily units.

The cleaning, repair, and recovery times are estimated in an individual manner for all exposed assets included in the exposure database and afterwards summed (grouped in single or multifamily categories). For the cleaning, repair, 


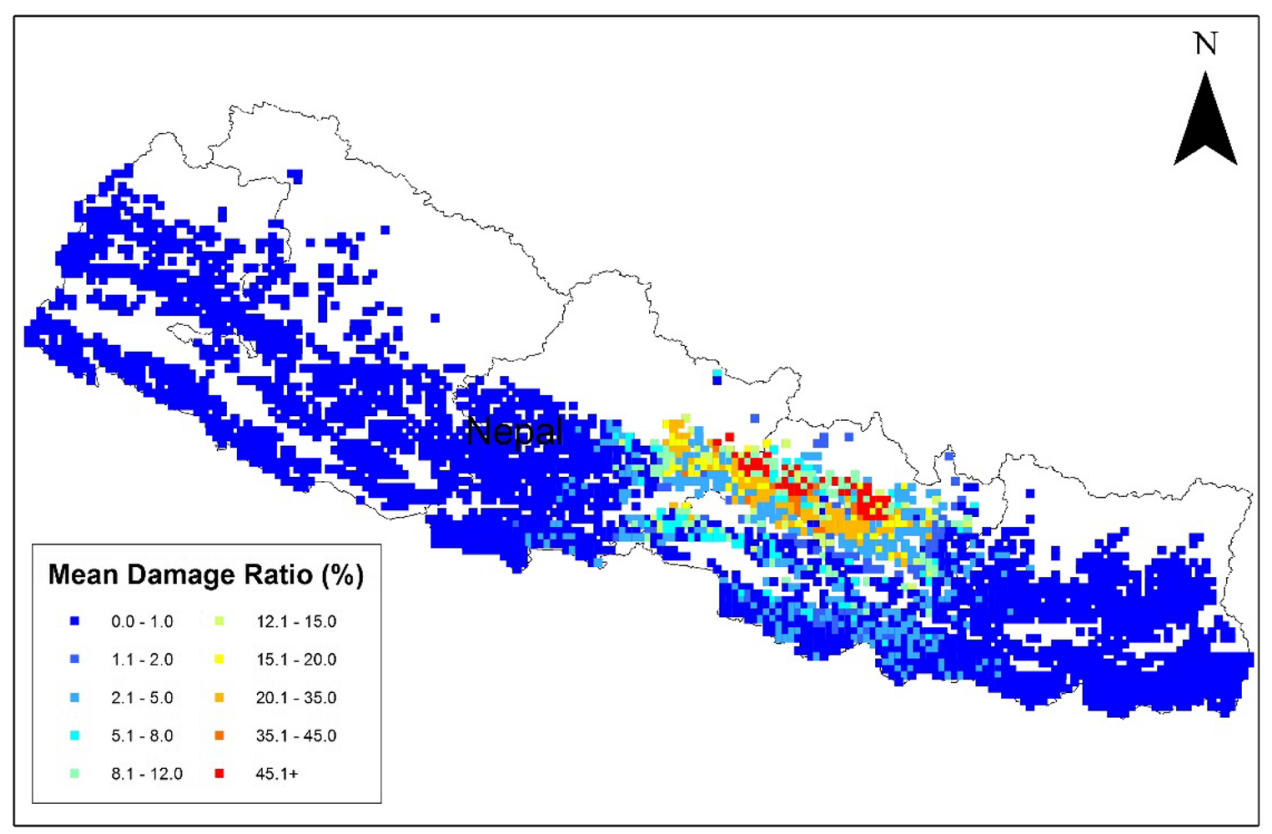

Fig. 4 MDR distribution for the residential buildings in Nepal

and recovery of single family units, 670 years are needed whereas for the multifamily units, 436 years are required.

The sum of these figures is equal to 1106 and represents the cumulative number of years required for the recovery, repair, and cleaning of all the affected residential units at the country level due to the impact of this earthquake. To consider demand surge and supply shortage issues because of simultaneous damage in the domain under study, a delay factor equal to 1.1 is used. This delay factor is based on the overall MDR at the country level, which in this study has been estimated at $4.6 \%$. Therefore, the cumulative number of years required for cleaning, repair, and recovery purposes is equal to 1216 .

IDPs are estimated by using the functions described in the previous section of this article, which was obtained for the Gorkha April 2015 earthquake event, and results in an overall number of 3682,810 IDPs. This number represents the number of people who, because of the damage inflicted by the ground motion in their residences, could not return and immediately reoccupy their home. An advantage of modeling IDPs is that since human occupation is geolocated, the linkage between the IDPs and the displacement length at each entry in the database is directly made.

With the results obtained in the previous stages, it is possible to estimate the total number of years lost because of internal displacement. For this case, the life-lost years associated to single family units are equal to 587,061, whereas those related to multifamily units are equal to 544,920 . In total, 1,131,981 life years are lost.
To determine the working age in Nepal, the recommendation by the OCDE (everyone between 15 and 64 years old) was followed. The age distribution of Nepal was obtained from the dataset of the United Nations Population Division in which the working age population corresponds to $61.79 \%$ of the total, around $17,600,000$ people. This figure is later affected by the share of the labor force rate, which for Nepal in 2015 was equal to $86.2 \%$ (World Bank 2018) and by considering an unemployment rate equal to $3.1 \%$. With this, it is possible to estimate the YLD of the employed population, which equals to 584,237 life-lost years.

Finally, the combination of the YLD associated to the employed group and the GDP per capita of Nepal was used to estimate the lost economic production because of internal displacement due to the 2015 earthquake triggering event. GDP per capita has been taken from the World Bank (2018) data, at USD 695. With these results, the estimated cost of the lost economic production is about USD 406 million. If, for instance, instead of the GDP per capita (that can likely underestimate the indirect losses), GDP per employed person is used (USD 1455 for Nepal in 2015), the lost economic production because of internal displacement triggered by this earthquake is around USD 850 million. 


\section{Discussion}

The methodology presented in this study can be used in both retrospective and prospective manners. The latter approach is far more useful in disaster risk management since it provides the opportunity to determine potential direct and indirect losses in several dimensions that in this case, also include IDPs. The proposed methodology is fully scalable, meaning that when the required data are available it can be adapted to produce global, national, subnational, and/or local estimates. Despite the coarse-grain resolution level adopted for the exposure representation in this study, the results presented at the national level are useful for a quantitative estimation of indirect economic impacts of internal displacement.

Previous prospective assessments of IDPs because of natural hazards provided only the overall figure of affected people without accounting for the displacement length. The latter is a useful outcome that can be estimated with the methodology proposed in this article, and it adds information that can be useful to humanitarian and development organizations that can plan in advance for management and running costs of displacement camps.

Currently, the methodological framework on which this proposal stands requires a particular representation of the triggering event, using a characterization of its temporal occurrence frequency and also by accounting for the geographical distribution of the hazard intensities (for example, ground accelerations, flood depths, wind speeds, and so on). Future research for the integration of hazards with anthropogenic origin and/or conflict situations-another important driver of IDPs at the global level-is needed.

The development of local recovery, repair, and cleaning time functions is also an aspect that, given its relevance in the lost economic production assessment as a consequence of internal displacement, requires attention, documentation, and future research. Although today's available data allow a good approximation, local conditions under certain stresses caused by economic shocks can result in important differences and modify the overall results.

Quantitative estimates of the lost economic production because of internal displacement have the potential to aid governments and humanitarian and development stakeholders to address the phenomena in a more effective manner, therefore limiting the negative impacts that such losses can have on the lives of all those affected, not only IDPs but also host communities.

\section{Conclusions}

The use of a quantitative approach to estimate the lost economic production because of forced internal displacement represents a notable change in the way that these assessments have been performed. In the past, only qualitative estimations have been performed, including a series of limitations that did not allow their application at national and regional scales. One relevant outcome of this proposed methodology is the generation of a figure that reliably approximates the indirect cost of internal displacement, which can serve as a basis for the encouragement of future investments in preventive measures that affect IDPs. This could represent a notable paradigm shift from a reactive approach to one more focused on the risk management, a strategy that has proven to be far more cost-effective, limits the impacts of those affected, and allows a more articulated integration of the topic into development, humanitarian, and sustainability agendas at the local and global levels.

The presented methodology focuses on two key areas in which internal displacement can affect the normal functioning of local economies. These are: (1) housing and infrastructure and (2) lost economic production. This model heavily accounts for the latter by estimating the cost of reduced production, and in a sense also by the affection in consumption, in the areas of origin together with an approximate estimation of the overall time of internal displacement. The latter is a useful indicator, for instance to be used in determining the costs of running and managing displacement camps.

An additional field of application of this methodology include the educational and health sectors. On these, the assessment of lost years of schooling and the evaluation of healthcare services based on the structural damage inflicted on these facilities can be performed. Despite not being directly related to the housing sector, the disruption in these two sectors also have immediate and longer-term consequences with economic impacts on IDPs, their welfare, and the normal functioning of host communities.

The quantification of the lost economic production because of internal displacement is a useful activity in disaster risk management and planning. Addressing all the variables and features that can add to the economic impact of internal displacement in a quantitative manner, in this case by estimating the lost economic production, provides good reasons on why this impact should be quantified as such, and on why the outcomes of the assessment provide relevant information for policy and decision makers.

Acknowledgements The author is thankful to IDMC, specially to Christelle Cazabat, Bina Desai, Mark Lambiris, and Justin Ginnetti for making available their model datasets and for the fruitful discussions around this topic in the framework of the project "Analyzing 
the economic impacts of internal displacement" funded by the Office of U.S. Foreign Disaster Assistance. Also, the author is grateful to the four reviewers whose comments contributed to improve the original version of this manuscript.

Open Access This article is distributed under the terms of the Creative Commons Attribution 4.0 International License (http://crea tivecommons.org/licenses/by/4.0/), which permits unrestricted use, distribution, and reproduction in any medium, provided you give appropriate credit to the original author(s) and the source, provide a link to the Creative Commons license, and indicate if changes were made.

\section{References}

Aijazi, O. 2014. Theorizing a social repair orientation to disaster recovery: Developing insights for disaster recovery policy and programming. Global Social Welfare 2(1): 15-28.

Amirthalingam, K., and R.W.D. Lakshman. 2009. Displaced livelihoods in Sri Lanka: An economic analysis. Journal of Refugee Studies 22(4): 502-524.

Cardona, O.D. 2001. Holistic seismic risk assessment using complex dynamic systems (Estimación holística del riesgo sísmico utilizando sistemas dinámicos complejos). Ph.D. thesis. Barcelona: Polytechnic University of Catalonia (in Spanish).

Cardona, O.D., M. Ordaz, E. Reinoso, L.E. Yamín, and A.H. Barbat. 2012. CAPRA - Comprehensive approach to probabilistic risk assessment: International initiative for risk management effectiveness. In Proceedings of the 15th World Conference on Earthquake Engineering, 24-28 September 2012, Lisbon, Portugal. 4259. Sociedade Portuguesa de Engenharia Sismica. ISBN: 978-1-63439-651-6.

Cardona, O.D., M.G. Ordaz, M. Mora, M.A. Salgado-Gálvez, G.A. Bernal, D. Zuloaga-Romero, M.C. Marulanda, L. Yamín, and D. González. 2014. Global risk assessment: A fully probabilistic seismic and tropical cyclone wind risk assessment. International Journal of Disaster Risk Reduction 10(Part B): 461-476.

Cazabat, C. 2018. The elephant in the room: As governments gathered in New York to discuss progress towards sustainable development, many omitted internal displacement. http://internal-displa cement.org/expert-opinion/the-elephant-in-the-room-as-govern ments-gathered-in-new-york-to-discuss-progress. Accessed 3 Sept 2018.

De Bono, A., and B. Chatenoux. 2015. A global exposure model for GAR 2015. Background paper prepared for the global assessment report on disaster risk reduction 2015. Geneva: UNEP.

Devleesschauwer, B., A.H. Havelaar, C.M. de Noordhout, J.A. Haagsma, N. Praet, P. Dorny, L. Duchateau, P.R. Torgeson, H. Van Oyen, and N. Speybroeck 2014. DALY calculation in practice: A stepwise approach. International Journal of Public Health 59(3): 571-574.

FEMA (Federal Emergency Management Agency). 2017a. Hazus-MH 2.1 flood model technical manual. Washington, DC: FEMA.

FEMA (Federal Emergency Management Agency) 2017b. Hazus-MH 2.1 earthquake model technical manual. Washington, DC: FEMA.

Ginnetti, J., L. Milano, and C. Velásquez. 2017. Global displacement risk- model. Geneva: IDMC.

IDMC (Internal Displacement Monitoring Center). 2017. 2017 global report on internal displacement (GRID 2017). Geneva: IDMC.

IDMC (Internal Displacement Monitoring Center). 2018. 2018 global report on internal displacement (GRID 2018). Geneva: IDMC.

Lamego, P., P.B. Lourenco, M.L. Sousa, and R. Marques. 2017. Seismic vulnerability and risk analysis of the old building stock at urban scale: Application to a neighborhood in Lisbon. Bulletin of Earthquake Engineering 15(7): 2901-2937.

Larson, B.A. 2013. Calculating disability-adjusted life-years lost (DALYs) in discrete-time. Cost effectiveness and resource allocation 11: Article 18.

Mamula-Seadon, L. 2015. Earthquake disaster recovery: Leadership and governance. In Encyclopedia of earthquake engineering, ed. M. Beer, I. Kougioumtzoglou, E. Patelli, and I.K. Au, 1-14. Heidelberg, Berlin: Springer.

Mouroux, P., and B. Le Brun. 2006. Presentation of the RISK-UE project. Bulletin of Earthquake Engineering 4(4): 323-339.

Noy, I. 2014. A non-monetary global measure of the direct impact of natural disasters. Wellington: School of Economics and Finance, Victoria University.

OECD (Organisation for Economic Co-operation and Development). 2018. OECD labour force statistics 2017. Paris: OECD Publishing.

Ordaz, M. 2000. Seismic risk assessment methodology focused on the management of earthquake insurance (Metodología para la evaluación del riesgo sísmico enfocada a la gerencia de seguros por terremoto). Universidad Nacional Autónoma de México. México D.F.

Ordaz, M. 2015. A simple probabilistic model to combine losses arising from simultaneous occurrence of several hazards. Natural Hazards 76(1): 389-396.

Pribadi, K.S., D. Kusumastuti, S.A.H. Sagala, and R. Wimbardana. 2014. Post-disaster housing reconstruction in Indonesia: Review and lessons from Aceh, Yogyakarta, West Java and West Sumatera earthquakes. In Disaster recovery: Used or misused development opportunity, ed. R. Shaw, 197-223. Tokyo: Springer.

Salgado-Gálvez, M.A., A.H. Barbat, O.D. Cardona, and M.L. Carreño. 2016. Comparing observed damages and losses with modelled ones using a probabilistic approach: The Lorca 2011 case. International Journal of Disaster Risk Reduction 19: $355-365$.

Salgado-Gálvez, M.A., G.A. Bernal, A.H. Barbat, M.L. Carreño, and O.-D. Cardona. 2016. Probabilistic estimation of annual lost economic production due to premature deaths because of earthquakes. Human and Ecological Risk Assessment 22(2): 543-557.

Salgado-Gálvez, M.A., R.D. Zuloaga-Romero, G.A. Bernal, M.G. Mora, and O.-D. Cardona. 2014. Fully probabilistic seismic risk assessment considering local site effects for the portfolio of buildings in Medellín, Colombia. Bulletin of Earthquake Engineering 12(6): 671-695.

Salgado-Gálvez, M.A., D. Zuloaga Romero, C.A. Velásquez, M.L. Carreño, O.-D. Cardona, and A.H. Barbat. 2016. Urban seismic risk index for Medellín, Colombia, based on probabilistic loss and casualties estimations. Natural Hazards 80(3): 1995-2021.

UN (United Nations). 2015. Sustainable development goals. https:// www.un.org/sustainabledevelopment/sustainable-developmentgoals/. Accessed 4 Sept 2018.

UNISDR (United Nations International Strategy for Disaster Risk Reduction). 2015. Global assessment report on disaster risk reduction 2015. Geneva: United Nations.

UNISDR (United Nations International Strategy for Disaster Risk Reduction). 2017. The GAR atlas, unveiling global disaster risk. Geneva: UNISDR.

USGS (United States Geological Survey). 2015. Shakemap atlas. https://earthquake.usgs.gov/earthquakes/eventpage/ us20002926\#executive. Accessed 15 Jun 2018.

WHO (World Health Organization). 2013. WHO methods and data sources for global burden of disease estimates 2000-2011. Geneva: WHO. 
World Bank. 2012. Guidelines for assessing the impacts and costs of forced displacement. Washington, DC: The World Bank.

World Bank. 2018. The World Bank data. https://data.worldbank.org/ indicator/SL.TLF.ACTI.ZS?end=2015\&start=1990. Accessed 1 Aug 2018.
Zhao, B. 2016. April 2015 Nepal earthquake: Observations and reflections. Natural Hazards 80(2): 1405-1410. 